\title{
Multilocus phylogeny and cryptic diversity of white-toothed shrews (Mammalia, Eulipotyphla, Crocidura) in China
}

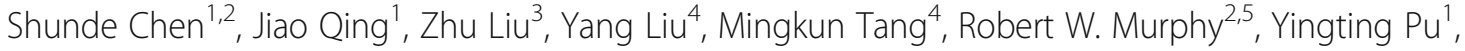
Xuming Wang ${ }^{1,4}$, Keyi Tang ${ }^{1}$, Keji Guo ${ }^{6}$, Xuelong Jiang ${ }^{2^{*}}$ and Shaoying Liu ${ }^{4^{*}}$

\begin{abstract}
Background: Crocidura, the most speciose mammalian genus, occurs across much of Asia, Europe and Africa. The taxonomy of Chinese representatives has been studied primarily based on cursory morphological comparisons and their molecular phylogenetic analyses remain unexplored. In order to understand the phylogeny of this group in China, we estimated the first multilocus phylogeny and conducted species delimitation, including taxon sampling throughout their distribution range.

Results: We obtained one mitochondrial gene (cytb) ( 1, $134 \mathrm{bp})$ and three nuclear genes (ApoB, BRCA1, RAG1) $(\sim$ 2, $170 \mathrm{bp})$ for 132 samples from 57 localities. Molecular analyses identified at least 14 putative species that occur within two major well-supported groups in China. Polyphyletic C. wuchihensis appears to be composed of two putative species. Two subspecies, C. rapax rapax and C. rapax kurodai should be elevated to full species status. A phylogenetic tree based on mitochondrial gene from Asian Crocidura species showed that the C. rapax rapax is embedded within C. attenuata, making the latter a paraphyletic group. Three strongly supported undescribed species (C. sp.1, C. sp.2 and C. sp.3) are revealed from Zada County of Tibet (Western China), Hongjiang County of Hunan Province (Central China) and Dongyang County of Zhejiang Province (Eastern China), Motuo County of Tibet, respectively. The divergence time estimation suggested that China's Crocidura species began to diversify during the late Pliocene (3.66 Ma) and the Early Pleistocene (2.29 Ma), followed by a series of diversifications through the Pleistocene.
\end{abstract}

Conclusions: The cryptic diversity found in this study indicated that the number of species is strongly underestimated under the current taxonomy. We propose that the three undescribed species should be evaluated using extensive taxon sampling and comprehensive morphological and morphometric approaches. Climate change since the late Pliocene and the uplift of the Qinghai-Tibet Plateau may result in the diversification and speciation of China's Crocidura species. In short, the underestimated diversity underlines the need for a taxonomic revision of Chinese Crocidura species.

Keywords: Mitochondrial DNA, Nuclear DNA, Rapid radiation, Soricidae, Species delimitation

\footnotetext{
* Correspondence: jiangxl@mail.kiz.ac.cn; Shaoyliu@163.com

${ }^{2}$ Kunming Institute of Zoology, Chinese Academy of Sciences, Kunming 650223, China

${ }^{4}$ Sichuan Academy of Forestry, Chengdu 610081, China

Full list of author information is available at the end of the article
}

(c) The Author(s). 2020 Open Access This article is distributed under the terms of the Creative Commons Attribution 4.0 International License (http://creativecommons.org/licenses/by/4.0/), which permits unrestricted use, distribution, and reproduction in any medium, provided you give appropriate credit to the original author(s) and the source, provide a link to the Creative Commons license, and indicate if changes were made. The Creative Commons Public Domain Dedication waiver (http://creativecommons.org/publicdomain/zero/1.0/) applies to the data made available in this article, unless otherwise stated. 


\section{Background}

Crocidura is the most speciose genus of all mammalian genera. Its 172 species occur broadly across much of Asia, Europe and Africa [1]. The highly conserved external morphologies of these species lead to their extreme taxonomic confusion [2, 3]. In China, species of Crocidura are among the most poorly understood mammals. The main challenge for taxonomy of Chinese Crocidura is the lack of available specimens. Some species and subspecies are only known from the holotypes. There are at least 19 recorded species and subspecies of Crocidura (Table 1). However, the taxonomic status and the number of species of Chinese Crocidura have changed over time (Table 1). For example, only 5 Crocidura species were recognized by Allen (1938) [4], while 8 species were listed by Honacki et al., 1982 [5]. Hutterer (1993) considered there were only 6 Crocidura species in China [6]. The current taxonomy recognizes 11 or 10 species $[7,8]$.

Chinese white-toothed shrews span Palearctic and Oriental faunal region (Fig. 1), but there have been only a few taxonomic studies of Chinese Crocidura. For example, one comprehensive morphological study enhanced the resolution of Crocidura from South China, and 6 species (C. attenuata, C. fuliginosa, C. rapax, $C$. vorax, $C$. shantungensis and $C$. horsfieldii) were recognized, and $C$. vorax and $C$. rapax, usually placed as synonyms of the European $C$. russula, are first recognized as 2 valid species [2]. Recently, a morphological and molecular study confirmed the presence of two white-toothed shrews (C. lasiura and C. shantungensis) in Northeast China [9]. The geographical distributions and morphological distinction of C. tanakae and C. attenuata were resolved based on a large number of specimens [10]. Compared with fewer studies in China, there are extensive studies of Crocidura in Southeast Asian countries and regions, such as in Vietnam [3, 11], Malaya and Indonesia [12-15], Philippines [16, 17] and Taiwan [17-19], Korea and Japan [20-23]. Although these previous studies did much to improve our understanding of the evolutionary relationships and taxonomy of Crocidura in Southeast Asian and regions, they rarely sampled species in China. The molecular phylogenetic relationships and genetic diversity of Crocidura within China remains largely unexplored.

Genetic investigations have often revealed systematic genetic relationships, as well as many cryptic species of small mammals, which is not surprising given their limited dispersal ability and morphological conservation [24-28]. Cryptic species of Crocidura may still exist within this widely distributed and diverse group of shrews [29-32], especially in the QinghaiTibetan Plateau and the Hengduan Mountains due to the extremely complex topography and variations in habitat [33].

In the last 20 years, we have collected more than 117 Crocidura specimens during our field surveys of small mammals through China. These specimens have expanded our knowledge concerning the distribution and habitats of Crocidura, but also allow us to re-examine the taxonomy of the genus in China. Herein, we evaluate extensive samples of Crocidura derived from China using a multilocus dataset and coalescent-based phylogenetic/species delimitation approaches. Our goals are (i) to determine if the diversity of Chinese Crocidura has been underestimated, (ii) to assess the phylogenetic

Table 1 Major classification systems of the genus Crocidura in China

\begin{tabular}{|c|c|c|c|c|c|c|}
\hline Allen (1938) [4] & $\begin{array}{l}\text { Honacki et al. } \\
\text { (1982) [5] }\end{array}$ & Hutterer (1993) [6] & $\begin{array}{l}\text { Jiang and Hoffmann } \\
(2001)[2]\end{array}$ & Hutterer (2005) [1] & $\begin{array}{l}\text { Hoffmann and } \\
\text { Lunde (2008) [7] }\end{array}$ & $\begin{array}{l}\text { Burgin and } \mathrm{He} \\
\text { (2018) [8] }\end{array}$ \\
\hline C. attenuata & C. attenuata & C. attenuata & C. attenuata & C. attenuata & C. attenuata & C. attenuata \\
\hline- & - & - & - & C. tanakae & C. tanakae & C. tanakae \\
\hline C. dracula & C. dracula & - & - & - & - & C. dracula \\
\hline- & C. fuliginosa & C. fuliginosa & C. fuliginosa & C. fuliginosa & C. fuliginosa & - \\
\hline- & C. horsfieldi & C. horsfieldii & C. horsfieldii wuchihensis & C. wuchihensis & C. wuchihensis & C. wuchihensis \\
\hline- & - & - & C. horsfieldii indochinensis & C. indochinensis & C. indochinensis & C. indochinensis \\
\hline- & C. lasiura & C. lasiura & C. lasiura & C. lasiura & C. lasiura & C. lasiura \\
\hline C. rapax & C. russula & - & C. rapax & C. rapax & C. rapax & C. rapax \\
\hline C. vorax & - & - & C. vorax & C. vorax & C. vorax & C. vorax \\
\hline- & C. sibirica & C. sibirica & C. sibirica & C. sibirica & C. sibirica & - \\
\hline- & C. suaveolens & C. suaveolens & - & - & - & C. suaveolens \\
\hline \multirow[t]{2}{*}{ C. ilensis } & - & C. dsinezumi & C. gmelini & C. gmelini & C. gmelini & - \\
\hline & - & & C. shantungensis & C. shantungensis & C. shantungensis & C. shantungensis \\
\hline
\end{tabular}




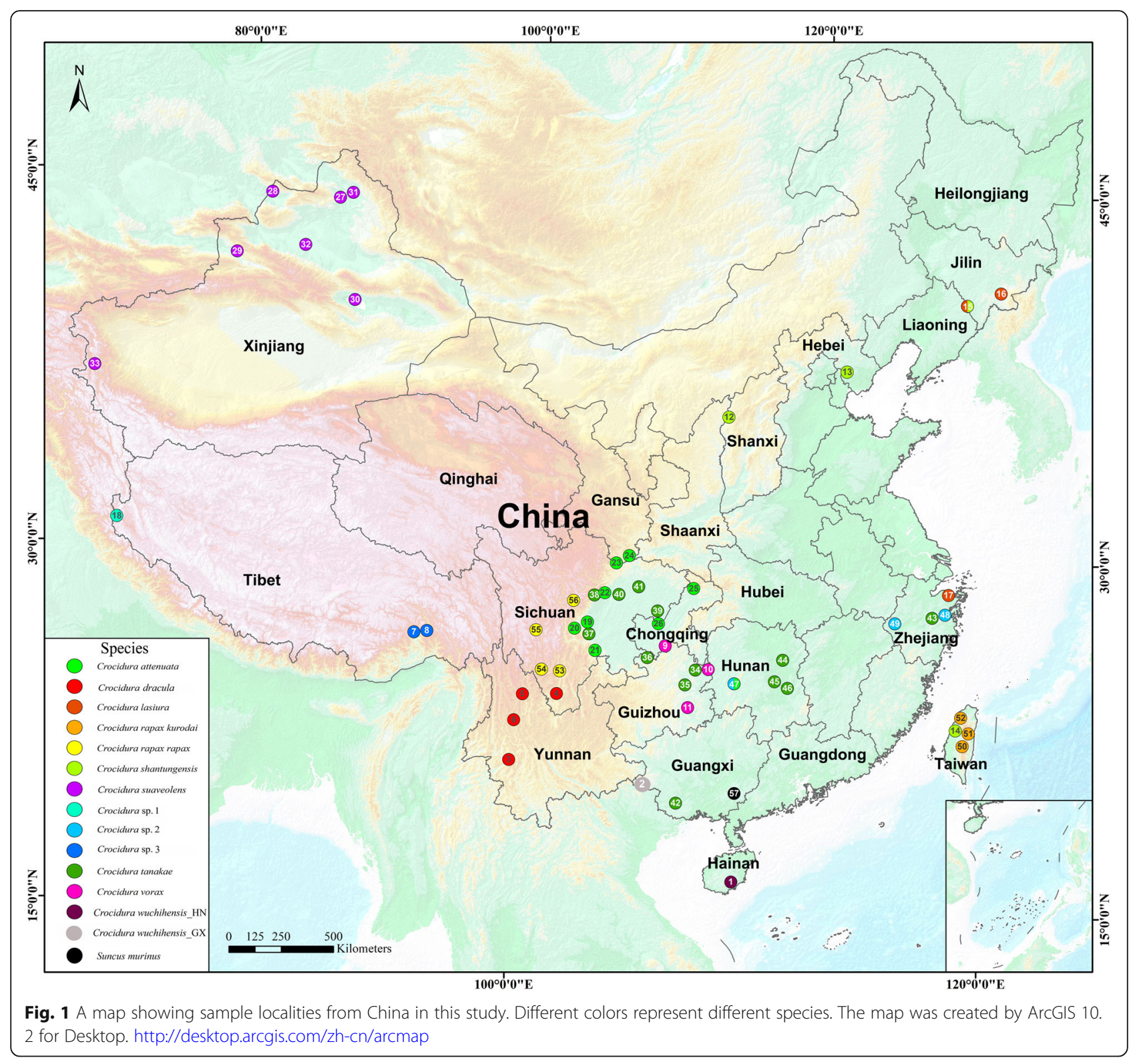

relationships among these species, and (iii) to explore the evolutionary history of Crocidura in China.

\section{Results}

\section{Sequence characteristics}

We obtained 117 new cytb sequences [1, 134 bp], 55 APOB [522 bp], 55 BRCA1 [793 bp] and 55 RAG1 [855 bp] sequences (Table 2). No stop codon was observed in the coding regions of the protein-coding genes. The mitochondrial genes showed relatively more genetic polymorphism when compared with the three nuclear genes (Additional file 1: Table S1). Newly generated sequences were deposited in GenBank (MN690740MN691036; Additional file 3: Table S3).
Phylogenetic analyses and molecular divergence times The phylogenies estimated by RAxML and BEAST were similar to each other for the first three molecular datasets (mtDNA, nDNA and mtDNA+ nDNA), and only the Bayesian Inference (BI) gene trees are shown (Fig. 2abc). In the BI and maximum likelihood (ML) trees, two wellsupported major monophyletic groups were recovered from the first three molecular datasets (Fig. 2abc). One group was made up of $C$. shantungensis, $C$. suaveolens and C. sp.1 from Zada County of Tibet (Western China) and was strongly determined in all analyses $(\mathrm{PP}=1.0, \mathrm{BS}=$ 100). In the other group, phylogenetic relationships among species were not fully resolved (Fig. 2abc). Crocidura dracula was divided into two well-supported subclades. One subclade was from Motuo County of Tibet ( $C$. 
Table 2 Information of samples used from China in this study

\begin{tabular}{|c|c|c|c|c|c|c|}
\hline Site & Detail Sample localities & Latitude & Longitude & Specimen Numbers & Species or subspecies & Source \\
\hline 1 & Mt. Diaoluo, Hainan, China & 18.722 & 109.868 & 3 & Crocidura wuchihensis_HN & This study \\
\hline 2 & Guangxi, China & 23.116 & 105.966 & 3 & Crocidura wuchihensis_GX & Genbank \\
\hline 3 & Mt. Yongde, Yunnan, China & - & - & 1 & Crocidura dracula & Genbank \\
\hline 4 & Miyi, Sichuan, China & 26.997 & 101.874 & 3 & Crocidura dracula & This study \\
\hline 5 & Lijiang, Yunnan, China & 26.927 & 100.229 & 3 & Crocidura dracula & This study \\
\hline 6 & Yangbi, Yunnan, China & 25.793 & 99.871 & 3 & Crocidura dracula & This study \\
\hline 7 & Motuo, Xizang, China & 29.244 & 95.015 & 2 & Crocidura sp. 3 & This study \\
\hline 8 & Motuo, Xizang, China & 29.326 & 95.326 & 3 & Crocidura sp. 3 & This study \\
\hline 9 & Mt.Jinfo, Chongqing, China & 29.049 & 107.194 & 1 & Crocidura vorax & This study \\
\hline 10 & Songtao, Guizhou, China & 27.992 & 108.783 & 1 & Crocidura vorax & This study \\
\hline 11 & Leigongshan, Guizhou, China & 26.385 & 108.203 & 1 & Crocidura vorax & This study \\
\hline 12 & Ningwu, Shanxi, China & 38.633 & 111.037 & 1 & Crocidura shantungensis & This study \\
\hline 13 & Zunhua, Hebei, China & 40.049 & 117.92 & 1 & Crocidura shantungensis & This study \\
\hline 14 & Taiwan, China & 24.166 & 120.633 & 1 & Crocidura shantungensis & Genbank \\
\hline \multirow[t]{2}{*}{15} & Xinbin, Liaoning, China & 41.604 & 125.391 & 3 & Crocidura shantungensis & This study \\
\hline & & & & 3 & Crocidura lasiura & This study \\
\hline 16 & Fusong, Jilin, China & 42.152 & 127.482 & 3 & Crocidura lasiura & This study \\
\hline 17 & Cixi, Zhejiang, China & - & - & 1 & Crocidura lasiura & Genbank \\
\hline 18 & Zada, Xizang, China & 31.783 & 78.872 & 1 & Crocidura sp. 1 & This study \\
\hline 19 & Mingshan, Sichuan, China & 30.076 & 103.178 & 3 & Crocidura attenuata & This study \\
\hline 20 & Yingjing, Sichuan, China & 29.804 & 102.679 & 4 & Crocidura attenuata & This study \\
\hline 21 & Muchuan,Sichuan,China & 28.876 & 103.714 & 1 & Crocidura attenuata & This study \\
\hline 22 & Pengzhou,Sichuan,China & 31.314 & 103.852 & 1 & Crocidura attenuata & This study \\
\hline 23 & Tangjiahe, Sichuan,China & 32.608 & 104.837 & 1 & Crocidura attenuata & This study \\
\hline 24 & Qingchuan,Sichuan,China & 32.912 & 105.432 & 6 & Crocidura attenuata & This study \\
\hline 25 & Kaixian, Chongqing, China & 31.455 & 108.712 & 1 & Crocidura attenuata & This study \\
\hline 26 & Huayingshan, Sichuan, China & 30.388 & 106.847 & 1 & Crocidura attenuata & This study \\
\hline 27 & Fuhai, Xinjiang, China & 47.075 & 87.427 & 2 & Crocidura suaveolens & This study \\
\hline 28 & Tacheng, Xinjiang, China & 46.732 & 83.028 & 1 & Crocidura suaveolens & This study \\
\hline 29 & Yining, Xinjiang, China & 43.911 & 81.731 & 1 & Crocidura suaveolens & This study \\
\hline 30 & Tulufan, Xinjiang, China & 42.857 & 89.192 & 1 & Crocidura suaveolens & This study \\
\hline 31 & Aletai, Xinjiang, China & 47.357 & 88.016 & 3 & Crocidura suaveolens & This study \\
\hline 32 & Mosuowan, Xinjiang, China & - & - & 2 & Crocidura suaveolens & Genbank \\
\hline 33 & Tashenkuergan, Xinjiang, China & 37.703 & 75.521 & 7 & Crocidura suaveolens & This study \\
\hline 34 & Mt. Fanjingshan, Guizhou, China & 27.984 & 108.64 & 2 & Crocidura tanakae & This study \\
\hline 35 & Shiqian, Guizhou, China & 27.364 & 108.11 & 1 & Crocidura tanakae & This study \\
\hline 36 & Hejiang, Sichuan, China & 28.571 & 106.294 & 2 & Crocidura tanakae & This study \\
\hline 37 & Mt.Emei, Sichuan, China & 29.571 & 103.399 & 2 & Crocidura tanakae & This study \\
\hline 38 & Dujiangyan, Sichuan, China & 31.233 & 103.650 & 2 & Crocidura tanakae & This study \\
\hline 39 & Huayingshan, Sichuan,China & 30.388 & 106.847 & 3 & Crocidura tanakae & This study \\
\hline 40 & Santai, Sichuan, China & 31.261 & 104.898 & 1 & Crocidura tanakae & This study \\
\hline 41 & Langzhong, Sichuan,China & 31.587 & 105.911 & 1 & Crocidura tanakae & This study \\
\hline 42 & Chongzuo, Guangxi,China & 22.274 & 107.510 & 3 & Crocidura tanakae & This study \\
\hline 43 & Dongyang, Zhejiang, China & 29.205 & 120.516 & 5 & Crocidura tanakae & This study \\
\hline
\end{tabular}


Table 2 Information of samples used from China in this study (Continued)

\begin{tabular}{|c|c|c|c|c|c|c|}
\hline Site & Detail Sample localities & Latitude & Longitude & Specimen Numbers & Species or subspecies & Source \\
\hline$\overline{44}$ & Yuelushan, Hunan,China & 28.189 & 112.945 & 3 & Crocidura tanakae & This study \\
\hline 45 & Hengshan, Hunan,China & 27.280 & 112.691 & 2 & Crocidura tanakae & This study \\
\hline 46 & Hengdong, Hunan,China & 26.970 & 113.067 & 1 & Crocidura tanakae & This study \\
\hline \multirow[t]{2}{*}{4} & \multirow[t]{2}{*}{ Hongjiang, Hunan,China } & \multirow[t]{2}{*}{27.327} & \multirow[t]{2}{*}{110.402} & 3 & Crocidura tanakae & This study \\
\hline & & & & 2 & Crocidura sp. 2 & This study \\
\hline 48 & Dongyang, Zhejiang, China & 29.205 & 120.516 & 7 & Crocidura sp. 2 & This study \\
\hline 49 & Qiandaohu, Zhejiang, China & 29.203 & 118.646 & 1 & Crocidura sp. 2 & This study \\
\hline 50 & Nantou, Taiwan, China & 23.668 & 120.988 & 3 & Crocidura rapax kurodai & Genbank \\
\hline 51 & Nantou, Taiwan, China & - & - & 3 & Crocidura rapax kurodai & Genbank \\
\hline 52 & Taichung,Taiwan, China, & - & - & 1 & Crocidura rapax kurodai & Genbank \\
\hline 53 & Jiulong, Sichuan, China & 27.977 & 101.996 & 1 & Crocidura rapax rapax & This study \\
\hline 54 & Muli, Sichuan, China & 28.019 & 101.102 & 2 & Crocidura rapax rapax & This study \\
\hline 55 & Yajiang, Sichuan, China & 29.680 & 100.754 & 1 & Crocidura rapax rapax & This study \\
\hline 56 & Xiaojin, Sichuan, China & 30.984 & 102.596 & 3 & Crocidura rapax rapax & This study \\
\hline 57 & Yulin, Guangxi, China & 22.595 & 110.220 & 4 & Suncus murinus & This study \\
\hline Total & & & & 132 & & \\
\hline
\end{tabular}

sp. 3), and another subclade was from Yunnan and $\mathrm{Si}$ chuan (C. dracula) (Fig. 2abc). Crocidura rapax and $C$. wuchihensis appeared polyphyletic species. Subspecies Crocidura r. kurodai from Taiwan and C. $r$. rapax from Chongqing and Guizhou did not form a monophyletic clade, as did C. wuchihensis from Hainan (C. wuchihensis $\mathrm{HN})$ and $C$. wuchihensis from Guangxi and Vietnam $(C$. wuchihensis_GX) (Fig. 2abc). Several sister-species relationships were also revealed, such as $C$. attenuata and $C$. r. rapax, Crocidura dracula and C. sp. 3 (Fig. 2abc). Notably, an undescribed species (C. sp. 2) from Hongjiang County of Hunan Province (Central China) and Dongyang County of Zhejiang Province (Eastern China) was revealed. Its phylogenetic position has not been resolved in mtDNA and nDNA trees (Fig. 2ab).

Phylogenetic relationships based on dataset 1(Fig. 2a) showed some differences compared to those obtained from datasets 4 (Fig. 3). For example, China's Crocidura species is a not monophyletic group, including some Crocidura undescribed species/species from other countries, such as C. zarudnyi from Iran, C. indochinensis, C. fuliginosa and C. zaitsevi from Vietnam, C. dsinezumi from Japan, and C. monticola, C. neglecta, C. maxi from Indonesia and Malaysia (Fig. 3). The C. fuliginosa complex was divided into three well-supported subclades, including $C$. sp. $3, C$. dracula and $C$. fuliginosa. When the $C$. attenuata samples from Vietnam were added, the phylogenetic tree showed that C. r. rapax was embedded within $C$. attenuata, making the latter a paraphyletic group (Fig. 3).
Divergence time estimates inferred that the most recent common ancestor (MRCA) of Asian Crocidura originated in the late Miocene period (6.10 Ma, highest posterior density (HPD) interval containing $95 \%$ of the sampled values: 4.72-7.69) (Fig. 3). China's Crocidura species began to diversify during the late Pliocene (3.66 $\mathrm{Ma})$ and the Early Pleistocene (2.29 Ma), followed by a series of diversifications through the Pleistocene (Fig. 3). The $C$. sp. 1 diverged from C. zarudnyi approximately $1.17 \mathrm{Ma}$ (95\% CI: 1.93-0.58). The C. suaveolens diverged from C. aff. Suaveolens approximately $0.54 \mathrm{Ma}(95 \% \mathrm{CI}$ : 0.89-0.27). The C. sp. 2 diverged from $C$. wuchihensis HN approximately $2.26 \mathrm{Ma}$ (95\% CI: 3.19-1.44). The $C$. sp. 3 diverged from C. fuliginosa approximately $1.04 \mathrm{Ma}$ (95\% CI: 1.63-0.60) and C. dracula approximately 1.93 Ma (95\% CI, 2.80-1.26).

\section{Species delimitation and species-trees}

The GMYC and BPP analyses gave identical results. GMYC species delimitation analysis recognized 14 (confidence interval $[\mathrm{CI}]=14-16$ ) putative species based on dataset 1 (mtDNA) (Fig. 2a). When using either dataset 2 (nDNA) or dataset 3 (mtDNA + nDNA), BPP consistently supported the validity of 14 hypothetical species with high posterior probabilities $(\mathrm{PP} \geq 0.94$; Additional file 2: Table S2). When using the time-calibrated gene tree as the input tree derived from dataset 4, SPLITS suggested that clades with divergence times earlier than $0.418 \mathrm{Ma}$ may have represented genetically distinct species (Fig. 3). In addition to supporting the 14 hypothetical species mentioned above, SPLITS also 


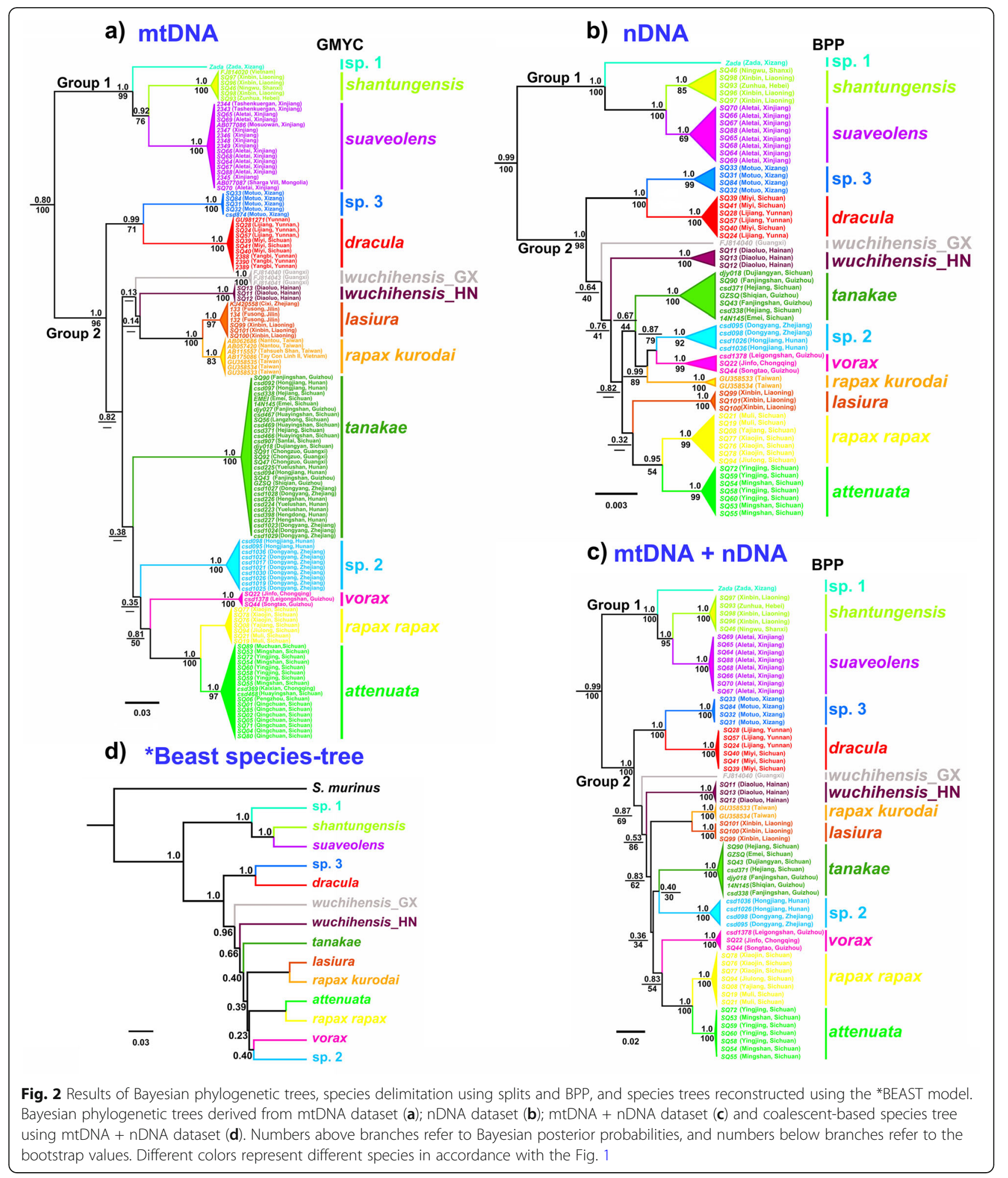

supported C. indochinesis, C. aff. Suaveolens and another C. attenuata population from Vietnam as a separate species (Fig. 3).

The "BEAST species-tree strongly divided species of Crocidura into two same groups as the concatenated and CYTB trees (Fig. 2ab), although the relationships within each group were not fully resolved. C. attenuata and C. r. rapax, C. dracula and C. sp. 3 were strongly supported as sister-taxa $(\mathrm{PP}=1.0)$, as were $C . r$. kurodai and C. lasiura ( $\mathrm{PP}=1.0)$ (Fig. $2 \mathrm{~d})$. 


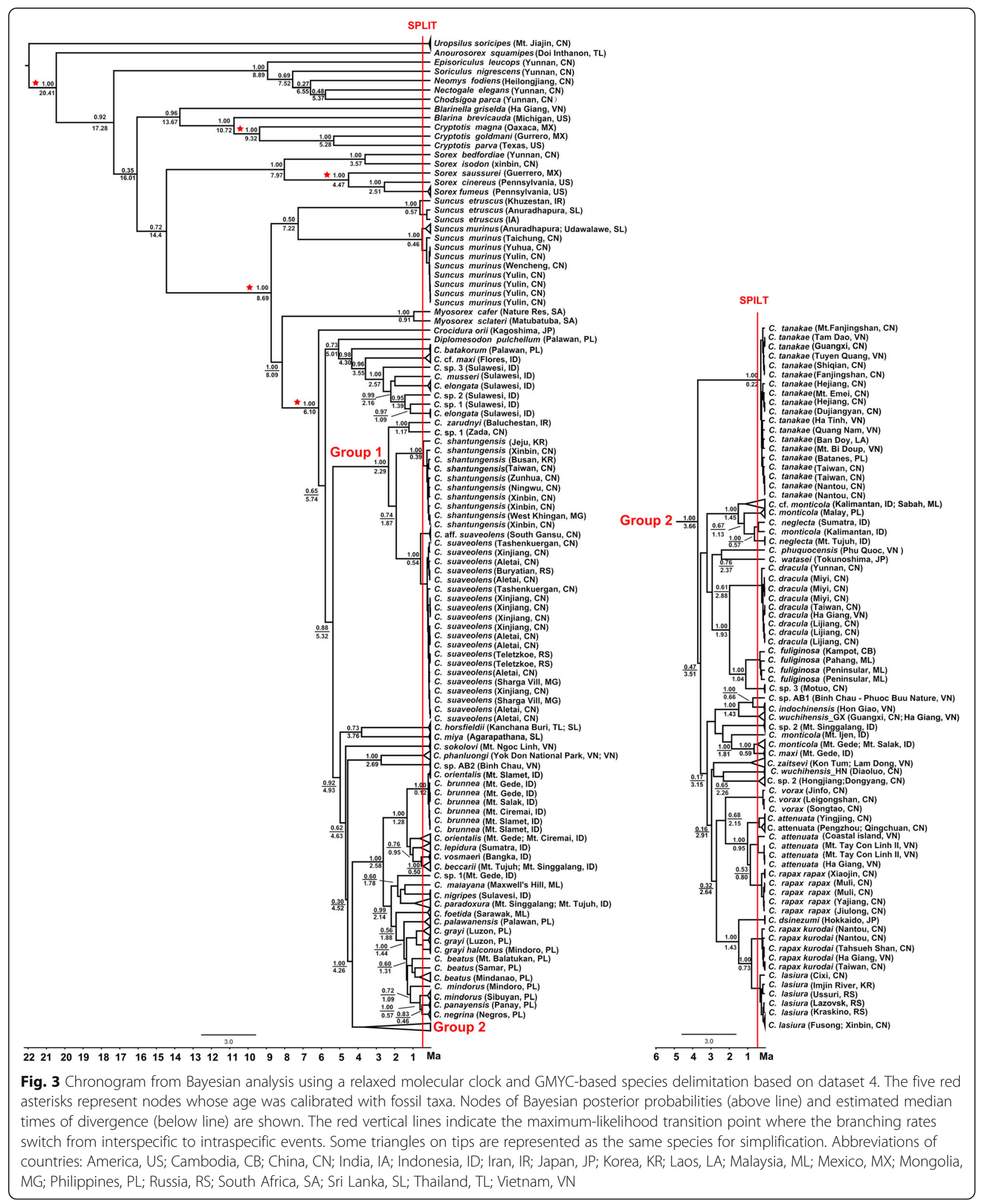




\section{Discussion}

\section{Mitochondrial and nuclear gene-trees discordance}

Our gene-trees inferred some conflicting or poorly supported phylogenetic relationships within Chinese Crocidura, and the molecular genetic interrelationships among several species are not consistent in mtDNA and nDNA trees (Fig. 2ab). This discordance could be attributed to explosive speciation [34], incomplete lineage sorting [35] and introgression [36-38]. Explosive speciation (i.e., rapid radiation) offers an explanation for the discrepancy owing to the very short branches that have poor support (Fig. 2). Our time-calibrated Bayesian analysis indicates rapid cladogenesis from the late Pliocene to the Early Pleistocene (Fig. 3), when most diversification occurred. Such rapid speciation can preclude high resolution of the phylogenetic trees because informative DNA substitutions will not have time to accumulate (e.g., $[39,40])$. A second explanation is that relatively recent radiation may not have provided enough time for a complete lineage sorting, further blurring the phylogenetic relationships of these species [41]. For example, there is a large genetic distance between C. sp. 2 and $C$. vorax and do not cluster together in mtDNA trees (Table 3), while relatively strong support for the clade C. sp. $2+$ C. vorax in nDNA tree. However, distinguishing the two hypotheses will require additional nuclear loci $[35,42]$. Another explanation for the discrepancy is an old introgression event, as reported in other shrews [37, 38]. For example, there is strong support for the clade C. lasuria + C. kurodai in mtDNA analysis and a small genetic distance between these two species (Table 3). However, these two species are very different and do not cluster together in nDNA trees.

\section{Phylogeny and rapid radiation among China's Crocidura species}

Our fine-scale sampling of Crocidura from China reveals two well-supported major groups of Crocidura (Fig. 2). Some species in the group 1 seemingly represents northwestern Crocidura species, while Some species in the group 2 represents south-eastern Crocidura species in China (Fig. 2). However, the phylogenetic relationships among many species in the group 2 remain unresolved (Fig. 2). To resolve phylogenetic relationships in recent, rapid radiation group, such as Crocidura, is a challenge task. Previous phylogenetic studies of Philippine Crocidura using multilocus data also yielded many poorly supported branches [14, 43]. Fortunately, phylogenomic analyses often have the potential to resolve difficult phylogenetic relationships $[44,45]$. However, using hundreds of ultraconserved elements (UCEs) and whole mitogenomes, Giarla and Esselstyn [46] could not fully resolve the phylogenetic relationships among the Philippine Crocidura based on coalescent-based approaches. Restriction site associated DNA sequencing (RADseq) is a commonly used approach for phylogeny estimation, and has been proved to be effective in solving some difficult phylogenetic relationships [45, 47, 48]. However, this RADseq could also lead to bias phylogenetic relationships when locus filtering techniques can not accurately identify homologous loci $[46,49]$. Thus, to completely resolve phylogenetic relationships using rapid high-throughput sequencing technology for this recent, rapid radiation Crocidura group may be still go a long way.

According to our divergence time estimation, China Crocidura species have rapidly diversified from the late Pliocene (3.66 Ma) to the early Pleistocene (2.29 Ma),

Table 3 The $p$-distance among undescribed species/species of Crocidura based on the cytb gene

\begin{tabular}{|c|c|c|c|c|c|c|c|c|c|c|c|c|c|}
\hline & $\begin{array}{l}\text { C. } \\
\text { suaveolens }\end{array}$ & $\begin{array}{l}\text { C. } \\
\text { dracula }\end{array}$ & $\begin{array}{l}\text { C. rapax } \\
\text { kurodai }\end{array}$ & $\begin{array}{l}\mathrm{C} . \\
\text { attenuata }\end{array}$ & $\begin{array}{l}\text { C. } \\
\text { shantungensis }\end{array}$ & $\begin{array}{l}\text { C. wuchihensis_ } \\
\text { GX }\end{array}$ & $\begin{array}{l}\text { C. } \\
\text { lasiura }\end{array}$ & $\begin{array}{l}\text { C. rapax } \\
\text { rapax }\end{array}$ & C. sp. 1 & C. sp. 2 & C. sp. 3 & C. tanakae & C. vorax \\
\hline C. dracula & 0.138 & & & & & & & & & & & & \\
\hline $\begin{array}{l}\text { C. rapax } \\
\text { kurodai }\end{array}$ & 0.140 & 0.119 & & & & & & & & & & & \\
\hline C. attenuata & 0.138 & 0.121 & 0.108 & & & & & & & & & & \\
\hline $\begin{array}{l}\text { C. } \\
\text { shantungensis }\end{array}$ & 0.084 & 0.140 & 0.134 & 0.141 & & & & & & & & & \\
\hline $\begin{array}{l}\text { C. wuchihensis_ } \\
\text { GX }\end{array}$ & 0.144 & 0.127 & 0.115 & 0.116 & 0.145 & & & & & & & & \\
\hline C. lasiura & 0.143 & 0.124 & 0.039 & 0.105 & 0.142 & 0.118 & & & & & & & \\
\hline C. rapax rapax & 0.142 & 0.126 & 0.108 & 0.049 & 0.149 & 0.108 & 0.111 & & & & & & \\
\hline C. sp. 1 & 0.088 & 0.138 & 0.136 & 0.139 & 0.093 & 0.132 & 0.137 & 0.142 & & & & & \\
\hline C. sp. 2 & 0.147 & 0.121 & 0.102 & 0.110 & 0.139 & 0.119 & 0.102 & 0.110 & 0.143 & & & & \\
\hline C. sp. 3 & 0.139 & 0.097 & 0.110 & 0.124 & 0.131 & 0.125 & 0.114 & 0.121 & 0.127 & 0.118 & & & \\
\hline C. tanakae & 0.134 & 0.116 & 0.105 & 0.120 & 0.151 & 0.121 & 0.107 & 0.115 & 0.142 & 0.114 & 0.117 & & \\
\hline C. vorax & 0.147 & 0.119 & 0.106 & 0.105 & 0.148 & 0.126 & 0.112 & 0.101 & 0.145 & 0.112 & 0.112 & 0.122 & \\
\hline $\begin{array}{l}\text { C. wuchihensis_ } \\
\mathrm{HN}\end{array}$ & 0.141 & 0.115 & 0.112 & 0.115 & 0.143 & 0.121 & 0.118 & 0.110 & 0.136 & 0.104 & 0.107 & 0.110 & 0.115 \\
\hline
\end{tabular}


followed by a series of diversifications through the Pleistocene (Fig. 3). What factors are responsible for the rapid diversification of Chinese Crocidura distributed? We propose that climate change and rapid uplifting of the Qinghai-Tibet Plateau may have driven the diversification of Chinese Crocidura. Prevailing trends towards cooling and desiccation at the Pliocene/Pleistocene boundary [50] have led to the diversification of some taxa (e.g., $[24,26,40])$. Shrews are extremely sensitive to changes in ambient temperature and humidity, which are key factors affecting the distribution and number of shrews [51]. An arid environment will most likely serve as a barrier to their dispersal, and subsequent allopatric diversification of Chinese Crocidura. At the same time, global cooling induced habitat turnover and consequent further accelerated the diversification, and eventually lead to the formation of Crocidura species in the region $[50,52]$. In addition, some geological studies also supported that rapid uplifting of the Qinghai-Tibet Plateau at $3.6 \mathrm{Ma}, 1.8 \mathrm{Ma}$ and $1.1 \mathrm{Ma}$ have resulted in the diversifications of Chinese Crocidura distributed on the $\mathrm{Ti}$ betan plateau $[53,54]$.

\section{Taxonomic implications and diversity of Crocidura in China}

Our data and analyses confirm the taxonomic status of the six well-recognized species: $C$. shantungensis, $C$. dracula, C. suaveolens, C. vorax, C. lasiura, and C. tanakae (Fig. 2; Additional file 2: Table S2). The mitochondrial and nuclear gene trees resolved each species as a welldemarcated clade, with substantial genetic differences between them (Table 3). Species delimitation analyses also identified each of them as a full species (Additional file 2: Table S2).

Jameson and Jones [55] originally described C. horsfieldii kurodai. Subsequently, Jiang and Hoffmann [2] revised the genus Crocidura in southern China and placed $C$. tadae and C. kurodai from Taiwan as junior synonyms of $C$. rapax. Hutterer [1] recognized three subspecies, $C$. rapax tadae, C. r. kurodai, and C. r. lutaoensis following Fang and Lee [19]. This view was followed by Hoffmann and Lunde [7], and Jenkins et al. [56]. Our analyses suggested the two subspecies, C. rapax rapax and C. rapax kurodai, should be elevated to full species status based on a high level of divergence (Table 3), GMYC and BPP analyses results (Fig. 3 and Additional file 2: Table S2).

Interestingly, when the $C$. attenuata samples from Vietnam were addedto the analysis, the phylogenetic tree showed that C. r. rapax was embedded within C. attenu$a t a$, making the latter a paraphyletic group (Fig. 3). Although the genetic distance value between these two species is only 0.049 , this distance value is greater than the genetic distance value $(=0.039)$ between $C$. kurodai and C. lasiura (Table 3). GMYC and BPP analysis strongly supported that they were two different species. We also examined a number of specimens including near type site specimens (Baoxing of Sichuan), and found that they were completely different in body size, skull size and altitude distribution (unpublished data). In addition, a C. attenuata population from Vietnam is supported as a separate species in GMYC. Therefore, a further research is needed to clarify the taxonomic status of the $C$. attenuata complex.

Crocidura wuchihensis was originally described in Hainan by Shou et al. [57]. Subsequently, Lunde et al. [58] identified one specimen from Vietnam as C. wuchihensis. Some specimens of Crocidura from Guangxi and Vietnam also have been referred to as $C$. wuchihensis [43]. Jenkins et al. [56] stated that C. wuchihensis was widely distributed across Vietnam, including the provinces Lao Cai, Ha Giang and Lang Son in the north and $\mathrm{Ha}$ Thinh and Quang Nam in Central Vietnam. Bannikova et al. [3] considered the distribution of C. wuchihensis to be restricted to areas east and north of the Red River. However, our analyses contradicted these assertions. Our analyses suggested that the population of $C$. wuchihensis_ $\mathrm{HN}$ from Hainan and those of C. wuchihensis_GX from Guangxi and Vietnam are valid species, which implies that the true C. wuchihensis may only occur on Hainan Island. Our results call for the reappraisal of the taxonomic status of shrews previously referred to as $C$. wuchihensis from Guangxi and Vietnam.

Crocidura indochinesis were previously considered a subspecies of $C$. horsfieldii [59]. Subsequent, Lunde et al. [60] considered $C$. indochinesis from Ke Go Nature Reserve, Vietnam as a full species. Our GMYC analysis strongly supported it as a species. It is still unknown whether $C$. indochinesis is distributed in China, because we do not know if the population in southern China is the conspecific with those in Vietnam.

Crocidura suaveolens is not known in China [2]. However, Dubey et al. [61] and Bannikova et al. [62] considered C. sibirica distributed in Xinjiang province (Northwest China) as Crocidura suaveolens, based on multilocus phylogenetic data. Subsequently, specimens of $C$. aff. Suaveolens have been reported from southern Gansu (Northwest China) [63]. These specimens formed the sister-group of $C$. suaveolens in our phylogenic trees. Our GMYC analysis supported the population (C. aff. suaveolens) as a potential species (Fig. 3). In addition, Jiang and Hoffmann [2] listed C. gmelini from Central Asia, including Xinjiang in China. However, Ohdachi et al. [22] stated "It is possible that C. gmelini might be a synonym of C. sibirica (=C. suaveolens)". All our Crocidura specimens from seven sample sites of Xinjiang in China appear to be C. suaveolens (Fig. 1). Therefore, it is necessary to sample $C$. gmelini to clarify the phylogenetic relationships and taxonomy between it and $C$. 
suaveolens. The occurrence of C. gmelini in China remains uncertain.

Crocidura dracula Thomas, 1912 [64] was first described from Mengzi County of Yunnan Province, China. Subsequently, the taxonomic decision was followed by Allen [4] and Ellerman and MorrisonScott [65]. However, Jenkins [66] made C. dracula a subspecies of $C$. fuliginosa. Others have followed the arrangement $[1,2]$. However, chromosomal and recently genetics studies suggested that $C$. dracula and C. fuliginosa are two different species $[3,8,11,29$, 67]. Burgin and $\mathrm{He}$ [8] considered these two forms as full species. Our analyses also supported three clades of C. fuliginosa groups that represented three different species: $C$. dracula from Northern Vietnam and southern China, C. fuliginosa from southern Vietnam, Cambodia and Malaysia, and undescribed species $(C$. sp. 3) from Motuo of Xizang (West China). It is worth noting that the conspecificity of C. fuliginosa from Southern Vietnam, Cambodia and Malaysia with the type locality in Burma has still not been tested. In addition, a population was also reported as $C$. dracula grisescens in Zhejiang [68]. Jiang and Hoffmann [2] supposed that the population represents probably new taxon.

Our analyses also resolved another undescribed species, Crocidura sp. 1, despite only one specimen being available from Zada Coutry in Tibet. This species is closely related to the Zarudny's rock shrew (Crocidura zarudnyi) from Iran based on the cytb gene. It is the sister-group of $C$. shantungensis and C. suaveolens based on nuclear genes. The condyloincisive length of the undescribed white-toothed shrew $(19.55 \mathrm{~mm}$; our unpublished data) is close to C. attenuata in China. Despite considerable effort, only one specimen was collected. Thus, our conclusions are therefore tentative. Additional fieldwork is needed to acquire new specimens and allow a comprehensive taxonomic and population genetic analysis. The continuous discovery of new species such as Bufo zamdaensis [69] and Laudakia papenfussi [70] shows a strong need for further exploration in the region.

Another undescribed species C. sp. 2 from Hongjiang County of Hunan and Dongyang County of Zhejiang was also strongly supported. It was not identified as any known species based on our morphological data. Genetically, it has a high level of divergence from all other members of the group (10.2-14.7\%) (Table 3) and appears as a monophyletic group in the phylogenetic trees (Fig. 2; Fig. 3). Thus, the C. sp. 2 is likely another new species. Molecular analyses offer important insights, but extensive sampling, comprehensive morphological and morphometric comparisons are necessary to reach a final conclusion.

\section{Conclusions}

In the present study, we obtained sequences of Crocidura throughout their distribution in China. We reconstructed the first multilocus phylogeny for the most speciose mammalian genus from China and found cryptic diversity. We propose that the three undescribed species should be evaluated using extensive taxon sampling and comprehensive morphological and morphometric approaches. Polyphyletic C. wuchihensis appears to be composed of two putative species. Two subspecies, $C$. rapax rapax and C. rapax kurodai should be elevated to full species status. Climate change since the late Pliocene periods and the uplift of the Qinghai-Tibet Plateau may have resulted in the diversification and speciation of China's Crocidura species. In short, the underestimated diversity underlines the need for a taxonomic revision of Chinese Crocidura species.

\section{Methods}

Taxon sampling and data collection

A total of 117 Crocidura shrews from 49 localities in China were collected from 1997 to 2017 (Table 2; Fig. 1). Specimens were identified based on their morphology and distributions following Jiang and Hoffmann [2], and Hoffmann and Lunde [7]. If specimens were not able to be assigned to known species, they were assigned tentative into undescribed species. All field studies and lab work were approved by the Guidelines for Care and Use of Laboratory Animals and the Ethics Committee at Sichuan Normal University (Chengdu, China). These Crocidura shrews were caught throng Sherman trap, snap trap and pitfalls (plastic buckets that were $14 \mathrm{~cm}$ in diameter and $20 \mathrm{~cm}$ in depth), and then immediately euthanized by cervical dislocation. All efforts were made to minimize potential pain and suffering. Voucher specimens were deposited in the Nature Museum of the Sichuan Academy of Forestry and Sichuan Normal University. Muscle or liver tissue was collected and preserved in 95\% ethanol and subsequently stored at $-80^{\circ} \mathrm{C}$ for molecular studies.

To test phylogenetic relationship and divergence time estimation between Chinese Crocidura and the Crocidura shrews from Asia (including East Asia, South Asia and Southeast Asia), we also downloaded 214 cytb sequences from 70 species/ undescribed species available in GenBank for comparison (Additional file 3: Table S3). These taxa sampling also included 26 species including representatives of subfamily Myosoricinae (Myosorex), Soricinae (Cryptotis, Otisorex, Anourosorex, Chodsigoa, Blarina) and Crocidurinae (Suncus) as several external fossil calibration points for divergence time estimation (Additional file 3: Table S3). Divergence time trees were rooted by the sequences of Uropsilus soricipes. In adittion, Sequences of Suncus murinus of the subfamily 
Crocidurinae were chosen as outgroup for phylogenetic relationship inferring.

\section{DNA extraction and amplification}

Total genomic DNA was extracted from muscle or liver using the phenol/proteinase $\mathrm{K} /$ sodium dodecyl sulfate method [71]. Given that the phylogenetic relationship of this Crocidura genus was well solved based on these four genes in the previous study [15, 29], we amplified these four genes, including the mitochondrial gene encoding cytochrome $b(c y t b)$ and nuclear gene fragments encoding Apolipoprotein B $(A p o B)$, breast cancer susceptibility gene1 (BRCA1) and recombination activating gene 1 (RAG1).

Primer sets were taken from the literature (Additional file 4: Table S4). PCR amplifications were performed in a reaction volume mixture of $25 \mu \mathrm{l}$, containing 0.2 units of rTaq Polymerase (Takara, Dalian, China), $1 \times$ reaction buffer, $3 \mathrm{mM}$ of $\mathrm{MgCl}_{2}, 0.2$ $\mathrm{mM}$ of each dNTP, $0.4 \mathrm{mM}$ of each primer and approximately $100-500 \mathrm{ng}$ of genomic DNA. PCR products were checked on a $1.0 \%$ agarose gel and purified using ethanol precipitation. Purified PCR products were directly sequenced using the BigDye terminator Cycle kit v3.1 (Applied Biosystems, Foster City, CA, USA) and determined with an ABI 310 analyzer (Applied Biosystems).

\section{Phylogenetic analyses and divergence time estimation} All DNA sequences were edited with EditSeq (DNASTAR, Lasergene v7.1) as well as aligned and examined by eye in MEGA 5 [72]. We applied Bayesian inference (BI) and maximum likelihood (ML) methods to infer the phylogenetic relationships. BI analyses were performed using BEAST v1.7.5 [73]. Analyses were conducted on the following four datasets: 1) a cytb gene dataset (mtDNA); 2) a three nuclear genes combined dataset (nDNA); 3) an all gene combined dataset (mtDNA + nDNA); and 4) the same as dataset 1 but with the cytb sequences of Asian Crocidura species and outgroups downloaded from GenBank (Additional file 3: Table S3). Each BEAST analysis used partition-specific models for the four genes (cytb, ApoB, BRCA1 and RAG1). The best model of evolution for each gene was determined using jModeltest v2 [74] ranked by the Akaike Information Criterion (AIC) (Additional file 1: Table S1). BEAST analyses used unlinked substitute model, linked clock models, linked tree, a random starting tree, a birth-death process tree prior, a relaxed lognormal clock model, and the program's default prior distributions of model parameters.

We ran each analysis for 100 million generations, and sampled every 5000th generation. TRACER v1.6 [75] was used to confirm that the effective sample sizes (ESSs) were greater than 200 and the first 10\% of the generations were treated as burn-in. Posterior probabilities (PP) $>0.95$ were considered to be strongly supported [76]. ML analyses used RAxML v7.2.8 [77, 78] on the CIPRES Science Gateway v3.1 (http://www.phylo. org, [79]) and the GTRGAMMA model for each gene, as recommended. The analyses used the rapid bootstrapping algorithm [78] with 500 replicates.

Missing data will mislead estimates of branch lengths and affect the estimation of the divergence time [80]. We only used cytb (dataset 4) for the divergence time estimation for Asian Crocidura species because some species have no nuclear genes sequences available in GenBank (Additional file 3: Table S3). Due to the lack of a fossil record of this Crocidura group in Asia, a fossil calibration of a molecular clock was impossible. Following Jacquet et al. [81], we used five external calibration points derived from paleontological data of Soricomorpha to estimate times of divergence for the group. (1) The split between Soricinae and Crocidurinae - Myosoricinae is estimated to have occurred about $20 \mathrm{Ma}$ [51] (normal: mean $=20 \mathrm{Ma}$, standard deviation $=1$ ). (2) The oldest recorded Myosoricinae - Crocidurinae is dated to at least $12 \mathrm{Ma}$ ago [82] (lognormal: mean $=0$, stdve $=1$, offset $=12 \mathrm{Ma}$ ). (3) The oldest known Cryptotis is dated to $9 \mathrm{Ma}$ ago [83] (lognormal: mean $=0$, stdve $=$ 1 , offset $=9 \mathrm{Ma}$ ). (4) The oldest Otisorex is dated to $3.5 \mathrm{Ma}$ ago [84] (lognormal: mean $=0$, stdve $=1$, offset $=3.5 \mathrm{Ma}$ ). (5) The oldest Crocidura (C. kapsominensis) is dated to $6 \mathrm{Ma}$ ago [85] (lognormal: mean = 0 , stdve $=1$, offset $=6 \mathrm{Ma}$ ).

Times of divergence and their credibility intervals within Crocidura were inferred using Bayesian analysis implemented with BEAST v1.7.5 [73]. BEAST analyses used unlinked substitute model, linked clock models, linked tree, a random starting tree, a birthdeath process tree prior, a relaxed lognormal clock model, and the program's default prior distributions of model parameters. Each analysis was run for 100 million generations and sampled every 5, 000 generations. The convergence of the run was checked by implementing TRACER v1.6 and the runs were combined using the Log combiner module of BEAST with a burn-in of $10 \%$. All fossil calibration ages were treated as lognormal distributions [86] except the divergence between Soricinae and Crocidurinae-Myosoricinae, which was used as a constraint and thus treated as a normal distribution [30, 81, 87].

\section{Species delimitation and species tree}

We first calculated the $p$-distances for cytb (dataset 1) between all species/ putative species using MEGA 5 
[72]. We used the general mixed Yule-coalescent model (GMYC) [88, 89] methods to delineate species boundaries. The method is applicable for single-locus data. Our GMYC analyses were performed with mtDNA gene tree and the time-calibrated gene tree as the input tree derived from for dataset 1 and dataset 4 separately without outgroups, implemented in the $\mathrm{R}$ package SPILT [90].

We used Bayesian species-delimitation method to delineate species boundaries [91]. We tested the validity of our assignment of 14 putative species based on the results of SPLITS (see Results) using the guidetree-free implemented in BPP v. 3.1 [91]. Only dataset 2 (nDNA) and dataset $3(\mathrm{mtDNA}+\mathrm{nDNA})$ were included in the analysis. Both algorithms 0 and 1 were used to specify the rjMCMC moves between alternative models of species delimitation. Because primitively analyses showed that algorithms 0 and 1 produced similar results, algorithm 0 with fine tuning parameter was used for subsequent analysis. Gamma-distributed priors $(G)$ were used to specify the ancestral population size $(\theta)$ and root age $(\tau)$. Use of inappropriate priors can bias posterior probabilities of species delimitation, potentially yielding false positives [91]. Thus, we tested two population size/tree age combinations chosen in previously studies [15, 92-94]. Trial runs showed good mixing using the two population size/ tree age combinations. The two combinations were modeled to allow a range of speciation histories: shallow population size/ moderate divergence [G (2, 2000 for $\theta$ and G (2, 2000) for $\tau]$ and large population size/ moderate divergence $[G(1,10)$ for $\theta$ and $G(2,2000)$ for $\tau]$. The divergence time prior $(\tau)$ used a diffuse Gamma-distributed probability distribution $(2,2000)$. The mean is $2 / 2000=0.001$ (which means $0.1 \%$ of sequence divergence), which assumes that species split one million years ago if substitution rates are $2.2 \times 10^{-9}$ [95] and generation time is equal to 1 year. Each rjMCMC was run for 100,000 generations and sampled each 100 generations after discarding 10,000 generations as pre-burn-in.

The species tree was reconstructed for Chinese Crocidura based on a coalescent-based method implemented in "BEAST [96]. Suncus murinus was selected as outgroup. The analysis used the dataset 3 (mtDNA + nDNA). The best-fit models were calculated using jModeltest [74] and are provided in Additional file 1: Table S1. Samples were assigned to 15 putative species (including the outgroup species Suncus murinus) based on the results of SPLITS and BPP (see Results). We used the same priors as the phylogenetic analyses described above. Each analysis was run for 100 million generations and sampled every 5000th generation. Convergence of the run was checked using TRACER v1.6 and the runs were combined using the Log combiner module of BEAST with a burnin of $10 \%$.

\section{Supplementary information}

Supplementary information accompanies this paper at https://doi.org/10. 1186/s12862-020-1588-8

Additional file 1: Table S1. Haplotype diversity, nucleotide diversity and best substitution models for each gene used.

Additional file 2: Table S2. Posterior probabilities supporting undescribed species/species using different algorithms and priors.

Additional file 3: Table S3. Sampling information including localities and GenBank accession numbers for species used in this study.

Additional file 4: Table S4. Primers used for PCR and sequencing.

\section{Acknowledgements}

We thank Rui Liao, Dr. Shengcao Shi and Dr. Xiaoqi Mi for collecting the samples in the field. Prof. Yang qisen and Prof. Ge deyan of the Institute of Zoology of the Chinese Academy of Science for permission to examine specimens under their care.

\section{Authors' contributions}

Conceived and designed the experiments: XLJ and SYL. Performed the experiments: JQ YTP. Analyzed the data: SDC XMW KYT. Contributed materials/analysis tools: ZL YL MKT KJG. Wrote the paper: SDC RWM. All authors read and approved the final manuscript.

\section{Funding}

This research was funded by the National Natural Science Foundation of China (31970399; 31670388; 31272276); The second National Survey of Terrestrial Wildlife Resources in Tibet of China. China Postdoctoral Science Foundation (2015 M570801); The Project of Chengdu Municipal Science and Technology Bureau (2015-NY02-00369-NC). The funding body played no role in the design of the study and collection, analysis, and interpretation of data and in writing the manuscript.

\section{Availability of data and materials}

The accession numbers for all genetic data used in this study are provided in Additional file 3: Table S3.

\section{Ethics approval and consent to participate}

All animal experiments for this project were approved by the Ethics Committee of Sichuan Normal University. No human subjects were used in this study.

Consent for publication

Not applicable.

\section{Competing interests}

The authors declare that they have no competing interests.

\section{Author details}

${ }^{1}$ College of Life Sciences, Sichuan Normal University, Chengdu 610066, China. ${ }^{2}$ Kunming Institute of Zoology, Chinese Academy of Sciences, Kunming 650223, China. ${ }^{3}$ College of Life Science and Technology, Mudanjiang Normal University, Mudanjiang 157011, China. ${ }^{5}$ Sichuan Academy of Forestry, Chengdu 610081, China. ${ }^{5}$ Centre for Biodiversity and Conservation Biology, Royal Ontario Museum, 100 Queen's Park, Toronto M5S 2C6, Canada. ${ }^{6}$ Central South Forest Inventory and Planning Institute of State Forestry

Administration, Changsha 410014, China.

Received: 15 August 2019 Accepted: 27 January 2020

Published online: 14 February 2020

\section{References}

1. Hutterer R. Mammal species of the world: a taxonomic and geographic reference. In: Wilson DE, Reeder DAM, editors. editors Order Soricomorpha. Baltimore: John Hopkins University Press; 2005. p. 220-311.

2. Jiang $\mathrm{XL}$, Hoffmann RS. A revision of the white-toothed shrews (Crocidura) of southern China. J Mammal. 2001;82(4):1059-79. 
3. Bannikova AA, Abramov AV, Borisenko AV, Lebedev VS, Rozhnov W. Mitochondrial diversity of the white-toothed shrews (Mammalia, Eulipotyphla, Crocidura) in Vietnam. Zootaxa. 2011;2812(1):1-20.

4. Allen GM. The Mammals of China and Mongolia. Section 1. New York: Central Asiatic Expeditions of the American Museum of Natural History; 1938. p. 620.

5. Honacki JH, Kinman KE, Koeppl JW. Mammal species of the world. Lawrence: Allen Press and The Association of Systematics Collections; 1982. p. 694.

6. Hutterer R. Mammal species of the world. A taxonomic and geographic reference. In: Wilson DE, Reeder DM, editors. editors Order Insectivora. Washington: Smithsonian Institute Press; 1993. p. 69-130.

7. Hoffmann RS, Lunde D. A guide to the mammals of China. In: Smith AT, Xie Y, editors. Soricomorpha. Princeton, New Jersey: Princeton University Press; 2008. p. 297-327.

8. Burgin CJ, He K. Family Soricidae (shrew). In: Wilson DE, Russell AM, editors. Hand book of the mammals of the world: insectivores, sloths and colugos. Barcelona: Lynx Edicions; 2018. p. 474-530.

9. Liu Z, Zhang JS, Bai W, Liu H, Xie RX, Yang X, Tin ZM. Classification and distribution of Soricidae in northeastern China. Acta Therialaeica Sinica. 2019;39(1):8-26.

10. Li YY, Li HT, Motokawa M, Wu Y, Harada M, Sun HM, Mo XM, Wang J, Li YC. A revision of the geographical distributions of the shrews Crocidura tanakae and $C$ attenuata based on genetic species identification in the mainland of China. ZooKeys. 2019;869:147-60.

11. Abramov AV, Bannikova AA, Rozhnov W. White-toothed shrews (Mammalia, Soricomorpha, Crocidura) of coastal islands of Vietnam. ZooKeys. 2012;207:37-47.

12. Ruedi M. Phylogenetic evolution and biogeography of southeast Asian shrews (genus Crocidura: Soricidae). Biol J Linnean Soc. 1996;58(2):197-219.

13. Ruedi M, Auberson M, Savolainen V. Biogeography of Sulawesian shrews: testing for their origin with a parametric bootstrap on molecular data. Mol Phylogenet Evol. 1998;9(3):567-71.

14. Esselstyn JA. Maharadatunkamsi, Achmadi AS, Siler CD, Evans BJ. Carving out turf in a biodiversity hotspot: multiple, previously unrecognized shrew species co-occur on java island, Indonesia. Mol Ecol. 2013;22(19):4972-87.

15. Demos TC, Achmadi AS, Giarla TC, Handika H. Maharadatunkamsi, Rowe KC, Esselstyn JA. Local endemism and within-island diversification of shrews illustrate the importance of speciation in building Sundaland mammal diversity. Mol Ecol. 2016;25(20):5158-73.

16. Heaney LR, Ruedi M. Advances in the biology of shrews. In: Merritt JF, Kirkland GL, Rose RK, editors. edictors A preliminary analysis of biogeography and phylogeny of Crocidura from the Philippines. Special Publication of the Carnegie Museum of Natural History; 1994. p. 357-77.

17. Esselstyn JA, Oliveros CH. Colonization of the Philippines from Taiwan: a multi-locus test of the biogeographic and phylogenetic relationships of isolated populations of shrews. J Biogeogr. 2010;37(8):1504-14.

18. Fang YP, Lee LL, Yew FH, Yu HT. Systematics of white-toothed shrews (Crocidura) (Mammalia: Insectivora: Soricidae) of Taiwan: karyological and morphological studies. J Zool. 1997;242(1):151-66.

19. Fang YP, Lee LL. Re-evaluation of the Taiwanese white-toothed shrew, Crocidura tadae Tokuda and Kano, 1936 (Insectivora: Soricidae) from Taiwan and two offshore islands. J Zool. 2002;257(2):145-54.

20. Motokawa M, Suzuki H, Harada M, Lin LK, Koyasu K, Oda SI. Phylogenetic relationships among east Asian species of Crocidura (Mammalia, Insectivora) inferred from mitochondrial cytochrome b gene sequences. Zool Sci. 2000; 17(4):497-504.

21. Motokawa M, Yu HT, Harada M. Diversification of the white-toothed shrews of the genus Crocidura (Insectivora: Soricidae) in East and Southeast Asia. Mamm Study. 2005;30(sp1):S53-64.

22. Ohdachi SD, Iwasa MA, Nesterenko VA, Abe H, Masuda R, Haberl W. Molecular phylogenetics of Crocidura shrews (Insectivora) in east and Central Asia. J Mammal. 2004;85(3):396-403.

23. Ohdachi SD, Hasegawa M, Iwasa MA, Vogel P, Oshid T, Lin LK, Abe H. Molecular phylogenetics of soricid shrews (Mammalia) based on mitochondrial cytochrome b gene sequences: with special reference to the Soricinae. J Zool. 2006;270(1):177-91.

24. Wan T, He K, Jiang XL. Multilocus phylogeny and cryptic diversity in Asian shrew-like moles (Uropsilus, Talpidae): implications for taxonomy and conservation. BMC Evol Biol. 2013;13(1):232.

25. Yuan SL, Jiang XL, Li ZJ, He K, Harada M, Oshida T, Lin LK. A mitochondrial phylogeny and biogeographical scenario for Asiatic water shrews of the genus Chimarrogale: implications for taxonomy and low-latitude migration routes. PLoS One. 2013;8(10):e77156.

26. Chen SD, Sun ZY, He K, Jiang XL, Liu Y, Koju NP, Zhang XY, Tu FY, Fan ZX, Liu SY, Yue BS. Molecular phylogenetics and phylogeographic structure of Sorex bedfordiae based on mitochondrial and nuclear DNA sequences. Mol Phylogenet Evol. 2015;84:245-53.

27. Koju NP, He K, Chalise MK, Ray C, Chen Z, Zhang B, Wan T, Chen SD, Jiang $\mathrm{XL}$. Multilocus approaches reveal underestimated species diversity and interspecific gene flow in pikas (Ochotona) from southwestern China. Mol Phylogenet Evol. 2017;107:239-45.

28. He K, Shinohara A, Helgen KM, Springer MS, Jiang XL, Campbell KL. Talpid mole phylogeny unites shrew moles and illuminates overlooked cryptic species diversity. Mol Biol Evol. 2017;1(34):78-87.

29. Dubey S, Salamin N, Ruedi M, Barrière P, Colyn M, Vogel P. Biogeographic origin and radiation of the old world Crocidurine shrews (Mammalia: Soricidae) inferred from mitochondrial and nuclear genes. Mol Phylogenet Evol. 2008:48(3):953-63.

30. Fumagalli L, Taberlet P, Stewart DT, Gielli L, Hausser J, Vogel P. Molecular phylogeny and evolution of Sorex shrews (Soricidae: Insectivora) inferred from mitochondrial DNA sequence data. Mol Phylogenet Evol. 1999;11(2):222-35.

31. Hope AG, Speer KA, Demboski JR, Talbot SL, Cook JA. A climate for speciation: rapid spatial diversification within the Sorex cinereus complex of shrews. Mol Phylogenet Evol. 2012;64(3):671-84.

32. Igbokwe J, Nicolas V, Oyeyiola A, Obadare A, Adesina AS, Awodiran MO, Van Houtte N, Fichet-Calvet E, Verheyen E, Olayemi A. Molecular taxonomy of Crocidura species (Eulipotyphla: Soricidae) in a key biogeographical region for African shrews, Nigeria. CR Biol. 2019;342(3-4):108-17.

33. He K, Jiang XL. Sky islands of Southwest China. I: an overview of phylogeographic patterns. Chin Sci Bull. 2014;59(7):585-97.

34. Krause J, Unger T, Nocon A, Malaspinas AS, Kolokotronis SO, Stiller M, Soibelzon L, Spriggs H, Dear P, Briggs A, Bray S, O'Brien S, Rabeder G, Matheus P, Cooper A, Slatkin M, Paabo S, Hofreiter M. Mitochondrial genomes reveal an explosive radiation of extinct and extant bears near the Miocene-Pliocene boundary. BMC Evol Biol. 2008;8(1):220.

35. Edwards SV. Is a new and general theory of molecular systematics emerging? Evolution. 2009;63(1):1-19.

36. Funk D, Omland K. Species-level paraphyly and polyphyly: frequency, causes, and consequences, with insights from animal mitochondrial DNA. Annu Rev Ecol Evol Syst. 2003;34(1):397-423.

37. Mackiewicz P, Moska M, Wierzbicki H, Gagat P, Mackiewicz D. Evolutionary history and phylogeographic relationships of shrews from Sorex araneus group. PLoS One. 2017;12(6):e0179760.

38. Yannic G, Dubey S, Hausser J, Basset P. Additional data for nuclear DNA give new insights into the phylogenetic position of Sorex granarius within the Sorex araneus group. Mol Phylogenet Evol. 2010;57(3):1062-71.

39. Xiong Y, Brandley MC, Xu S, Zhou K, Yang G. Seven new dolphin mitochondrial genomes and a time-calibrated phylogeny of whales. BMC Evol Biol. 2009;9(1):20.

40. He K, Li YJ, Brandley MC, Lin LK, Wang YX, Zhang YP, Jiang XL. A multi-locus phylogeny of Nectogalini shrews and influences of the paleoclimate on speciation and evolution. Mol Phylogenet Evol. 2010;56(2):734-46.

41. Jackson JA, Baker CS, Vant M, Steel DJ, Medrano-Gonzalez L, Palumbi SR. Big and slow: phylogenetic estimates of molecular evolution in baleen whales (suborder Mysticeti). Mol Biol Evol. 2009;26(11):2427-40.

42. Townsend JP. Profiling phylogenetic informativeness. Syst Biol. 2007:56(2):222-31.

43. Esselstyn JA, Timm RM, Brown RM. Do geological or climatic processes drive speciation in dynamic archipelagos? The tempo and mode of diversification in southeast Asian shrews. Evolution. 2009;63(10):2595-610.

44. Mccormack JE, Faircloth BC, Crawford NG, Gowaty PA, Brumfield RT, Glenn TC. Ultraconserved elements are novel phylogenomic markers that resolve placental mammal phylogeny when combined with species-tree analysis. Genome Res. 2012;22(4):746-54.

45. Richart $\mathrm{CH}$, Hayashi CY, Hedin M. Data from: Phylogenomic analyses resolve an ancient trichotomy at the base of Ischyropsalidoidea (Arachnida, Opiliones) despite high levels of gene tree conflict and unequal minority resolution frequencies. Mol Phylogenet Evol. 2016;95(11):171-82.

46. Giarla TC, Esselstyn JA. The challenges of resolving a rapid, recent radiation: empirical and simulated phylogenomics of Philippine shrews. Syst Biol. 2015;64(5):727-40

47. Eaton DAR, Ree RH. Inferring phylogeny and introgression using RADseq data: An example from flowering plants (Pedicularis: Orobanchaceae). Syst Biol. 2013;62(5):689-706. 
48. Cruaud A, Gautier M, Galan M, Foucaud J, Saune L, Genson G, Dubois E, Nidelet S, Deuve T, Rasplus JY. Empirical assessment of RAD sequencing for interspecific phylogeny. Mol Biol Evol. 2014;31(5):1272-4.

49. Huang $H$, Knowles LL. Unforeseen consequences of excluding missing data from next-generation sequences: simulation study of RAD sequences. Syst Bio. 2014:56(3):357

50. Webb T, Bartlein P. Global changes during the last 3 million years: climatic controls and biotic responses. Annu Rev Ecol Syst. 1992;23(23):141-73.

51. Reumer JWF. Speciation and evolution in the Soricidae (Mammalia: Insectivora) in relation with the paleoclimate. Rev Suisse Zool. 1989;96(1):81-90.

52. Shepard DB, Burbrink FT. Phylogeographic and demographic effects of Pleistocene climatic fluctuations in a montane salamander, Plethodon fourchensis. Mol Ecol. 2009;18:2243-62.

53. Li J, Fang X. Uplift of the Tibetan plateau and environmental changes. Chin Sci Bull. 1999:44(23):2117-24

54. Xiao JL, An ZS. Three large shifts in east Asian monsoon circulation indicated by loess-paleosol sequences in China and late Cenozoic deposits in Japan. Palaeogeogr Palaeoclimatol Palaeoecol. 1999;154(3):179-89.

55. Jameson EW, Jones GS. The Soricidae of Taiwan. Proc Biol Soc Wash. 1977; 90:459-82.

56. Jenkins PD, Lunde DP, Moncrieff CB. Systematic mammalogy: contributions in honour of Guy G. Musser. In Voss RS, Carleton MC, editors. Descriptions of new species of Crocidura (Soricomorpha: Soricidae) from mainland Southeast Asia, with synopses of previously described species and remarks on biogeography. Bull Am Mus Nat Hist. 2009;331:356-405.

57. Shaw TH, Wang S, Lu CK, Chang LK. A survey of the mammals of Hainan Island, China. Acta Zootaxonomica Sinica. 1966;3:260-76 [In Chinese].

58. Lunde DP, Musser GG, Son NT. A survey of small mammals from MT. Tay con Linh II, Vietnam, with the description of a new species of Chodsigoa (Insectivora: Soricidae). Mammal Study. 2003;28(1):31-46.

59. Robinson HC, Kloss CB. New mammals from French Indo-China and Siam. Ann Mag Nat Hist. 1922;9(49):87-99.

60. Lunde DP, Musser GG, Ziegler T. Description of a new species of Crocidura (Soricomorpha: Soricidae, Crocidurinae) from Ke go nature reserve, Vietnam. Mammal Study. 2004;29(1):27-36.

61. Dubey S, Zaitsev M, Cosson JF, Abdukadier A, Vogel P. Pliocene and Pleistocene diversification and multiple refugia in a Eurasian shrew (Crocidura suaveolens group). Mol Phylogenet Evol. 2006;38(3):635-47.

62. Bannikova AA, Lebedev VS, Kramerov DA, Zaitsev MV. Phylogeny and systematics of the Crocidura suaveolens species group: corroboration and controversy between nuclear and mitochondrial DNA markers. Mammalia. 2006;70(1-2):106-19.

63. Sheftel BI, Bannikova AA, Fang Y, Demidova TB, Alexandrov DY, Lebedev VS, Sun $\mathrm{YH}$. Notes on the fauna, systematics and ecology of small mammals in southern Gansu, China. Biol Bull. 2018;45(8):898-912 [in Russian with English summary].

64. Thomas O. New species of Crocidura and Petaurista from Yunnan. Ann Mag Nat Hist. 1912;9(54):686-8.

65. Ellerman JR, Morrison-Scott TCS. Checklist of Palaearctic and Indian mammals 1758 to 1946. London: British Museum (Natural History); 1951.

66. Jenkins PD. Variation in Eurasian shrews of the genus Crocidura (Insectivora: Soricidae). Bull Br Mus Nat Hist Zool. 1976;30:271-309.

67. Ruedi M, Vogel P. Chromosomal evolution and zoogeographic origin of southeast Asian shrews (genus Crocidura). Experientia. 1995;51(2):174-8.

68. Zhu GY, Gu HQ. Crocidura (Insectivora: Soricidae) in Fauna of Zhejiang: Mammalia. Hangzhou: Zhejiang Science and Technology Publishing House; 1993. p. 19-23.

69. Fei L, Ye C, Huang Y, Chen X. Taxonomic studies on Bufo viridis from West China. Zool Res. 1999;20(4):294-300 [In Chinese]

70. Zhao EM. A new species of the genus Laudakia from Xizang (Tibet) autonomous region. Acta Zootaxon Sin. 1998;23(4):440-4 [In Chinese].

71. Sambrook J, Fritsch EF, Maniatis T. Molecular cloning: a laboratory manual (2nd edition). Cold Spring Harbor, NewYork: Cold Spring Harbor Laboratory Press; 1989.

72. Tamura K, Peterson D, Peterson N, Stecher G, Nei M, Kumar S. MEGA 5: molecular evolutionary genetics analysis using maximum likelihood, evolutionary distance, and maximum parsimony methods. Mol Biol Evol. 2011;28(10):2731-9.

73. Drummond AJ, Suchard MA, Xie D, Rambaut A. Bayesian phylogenetics with BEAUti and the BEAST 1.7. Mol Biol Evol. 2012;29(8):1969-73.

74. Darriba D, Taboada GL, Doallo R, Posada D. JModelTest 2: more models, new heuristics and parallel computing. Nat Methods. 2012;9(8):772.
75. Rambaut A, Drummond A. Tracer 1.6. University of Edinburgh, Edinburgh, United Kingdom; 2013.

76. Huelsenbeck J, Rannala B. Frequentist properties of Bayesian posterior probabilities of phylogenetic trees under simple and complex substitution models. Syst Biol. 2004;53(6):904-13

77. Stamatakis A. RAxML-VI-HPC: maximum likelihood-based phylogenetic analyses with thousands of taxa and mixed models. Bioinformatics. 2006; 22(21):2688-90.

78. Stamatakis A, Hoover P, Rougemont J. A rapid bootstrap algorithm for the RAxML web servers. Syst Biol. 2008;57(5):758-71.

79. Miller MA, Pfeiffer W, Schwartz T. Creating the CIPRES Science Gateway for inference of large phylogenetic trees. In: Gateway computing environments workshop (GCE), 2010. IEEE Computer Society. 2010:912-914.

80. Lemmon AR, Brown JM, Stanger-Hall K, Lemmon EM. The effect of ambiguous data on phylogenetic estimates obtained by maximum likelihood and Bayesian inference. Syst Biol. 2009;58(1):130-45.

81. Jacquet F, Denys C, Verheyen E, Bryja J, Hutterer R, Peterhans JCK, Stanley WT, Goodman SM, Couloux A, Colyn M, Nicolas V. Phylogeography and evolutionary history of the Crocidura olivieri complex (Mammalia, Soricomorpha): from a forest origin to broad ecological expansion across Africa. BMC Evol Biol. 2015;15(1):71.

82. Robinson P, Black CC. Vertebrate faunas from the Neogene of Tunisia. Ann Geol Surv Egypt. 1974;4:319-32.

83. Harris AH. In Fossil history of shrews in North America. In: Wojcik JM, Wolsan M, editors. editors Evolution of Shrews. Bialowieza: Mammal Research Institute, Polish Academy of Science; 1998. p. 121-32.

84. Maldonado JE, Vila C, Wayne R. Tripartite genetic subdivisions in the ornate shrew (Sorex ornatus). Mol Ecol. 2001;10(1):127-47.

85. Mein P, Pickford M. Late Miocene micromammals from the Lukeino formation (6.1 to 5.8 ma), Kenya. Bull Mens Soc Linn Lyon. 2006;75(4):183223.

86. Ho SYW, Shapiro B, Phillips M, Cooper A, Drummond AJ. Evidence for time dependency of molecular rate estimates. Syst Biol. 2007;56(3):515-22.

87. Jacquet F, Nicolas V, Colyn M, Kadjo B, Hutterer R, Akpatou B, Decher J, Cruaud $C$, Denys $C$. Forest refugia and riverine barriers promote diversification in the west African pygmy shrew (Crocidura obscurior complex, Soricomorpha). Zool Scr. 2013:43(2):131-48.

88. Fujisawa T, Barraclough TG. Delimiting species using single-locus data and the generalized mixed Yule coalescent approach: a revised method and evaluation on simulated data sets. Syst Biol. 2013;62(5):707-24.

89. Pons J, Barraclough TG, Gomez-Zurita J, Cardoso A, Duran DP, Hazell S, Kamoun S, Sumlin WD, Vogler AP. Sequence-based species delimitation for the DNA taxonomy of undescribed insects. Syst Biol. 2006;55(4):595-609.

90. Paradis E, Claude J, Strimmer K. APE: analyses of phylogenetics and evolution in R language. Bioinformatics. 2004;20(2):289-90.

91. Yang ZH, Rannala B. Bayesian species delimitation using multilocus sequence data. Proc Natl Acad Sci. 2010;107(20):9264-9.

92. Leaché $A D$, Fujita MK. Bayesian species delimitation in west African forest geckos (Hemidactylus fasciatus). Philos Trans R Soc London Ser B. 2010; 277(1697):3071-7.

93. Stanley WT, Hutterer R, Giarla TC, Esselstyn JA. Phylogeny, phylogeography and geographical variation in the Crocidura monax (Soricidae) species complex from the montane islands of Tanzania, with descriptions of three new species. Zool J Linnean Soc. 2015;174(1):185-215.

94. Giarla TC, Voss RS, Jansa SA. Hidden diversity in the Andes: comparison of species delimitation methods in montane marsupials. Mol Phylogenet Evol. 2014;70:137-51.

95. Kumar S, Subramanian S. Mutation rates in mammalian genomes. Proc Natl Acad Sci U S A. 2002:99:803-8.

96. Heled J, Drummond AJ. Bayesian inference of species trees from multilocus data. Mol Biol Evol. 2010;27(3):570-80

\section{Publisher's Note}

Springer Nature remains neutral with regard to jurisdictional claims in published maps and institutional affiliations. 